\title{
A CLINICAL REPORT ON CASES OF PRIMARY ATYPICAL PNEUMONIA CAUSED BY A NEW VIRUS ${ }^{1}$
}

\author{
By GORDON MEIKLEJOHN, MONROE D. EATON,2 AND WILLIAM vaN HERICK \\ (From the Research Laboratory of the California State Department of Public Health, Berkeley, and the \\ Department of Medicine, University of California Medical School, San Francisco)
}

(Received for publication August 16, 1944)

During the 10 years which have passed since the disease now designated as primary atypical pneumonia began to take form as a definite clinical entity, considerable progress has been made in studies of its clinical and epidemiological aspects (1). Progress in etiological studies, however, has been comparatively slow. The isolation of a number of infectious agents from single patients or small groups of patients (2 to 10) has made it clear that the clinical syndrome under discussion is of diverse etiology and that the human organism, like a variety of experimental animals, may show a somewhat similar clinical and pathological response when any one of a number of unrelated nonbacterial infectious agents is introduced into the lower respiratory tract. At the same time, there is no convincing evidence that the great majority of cases reported have been due to any of the viruses or rickettsiae isolated up to the present.

The discovery that an infectious agent in the sputum or lungs of patients with primary atypical pneumonia produced a pneumonic infiltration when inoculated intranasally into cotton rats (11) opened a new line of approach. Investigation was further facilitated by the subsequent demonstration that this agent, presumably a virus, multiplied when introduced from human material into the amniotic sac of the chick embryo and that suspensions of infected chick embryo tissues produced a similar pneumonic response in cotton rats and hamsters. The properties of this virus, which is apparently

\footnotetext{
1 The studies and observations on which this paper is based were supported by the International Health Division of The Rockefeller Foundation.

2 Representing the Commission on Influenza, Board for the Investigation and Control of Influenza and Other Epidemic Diseases in the Army, Preventive Medicine Service, Office of the Surgeon General of the United States Army.
}

not related to influenza virus (type A or B), psittacosis-like viruses, or the rickettsia of Q-fever, have been described elsewhere (12). It was found that serum taken early in the course of the disease failed to neutralize the virus, but that convalescent serum consistently protected the test animals. On the basis of this neutralization test, it has been possible to classify a group of cases of primary atypical pneumonia of a type which has, up to the present time, fallen into the category of unknown etiology.

The correlation of the clinical and pathological findings in the various types of primary atypical pneumonia with the responsible etiological agent constitutes an important problem at the present time. In a previous report (13), clinical, laboratory, and pathological data have been presented on a group of 10 patients with atypical pneumonia from whom psittacosis-like viruses were isolated. It was emphasized that infections due to those agents were comparatively rare and differed in certain important respects from those not due to psittacosis-like viruses. The purpose of this paper is to present similar data on another group of cases of primary atypical pneumonia, together with evidence that they were caused by this new atypical pneumonia virus. Criteria of proof of such an etiological relationship are (1) demonstration of virus in lung or sputum during the course of illness by animal inoculation or by adaptation to chick embryos, (2) demonstration of an increase in neutralizing antibody during or after recovery from the illness, or preferably (3) both.

The 16 cases presented represent that form of primary atypical pneumonia which has occurred frequently in this area during the past 4 years, either as an epidemic or endemic disease. The group is somewhat weighted in favor of the more severe cases because these are more readily 
investigated. It is of considerable interest that most of the patients in the group developed significant titers of cold agglutinins (14).

\section{MATERIAL AND METHODS}

Clinical material. The cases studied, with one exception, were selected from a larger group of approximately 100 cases which occurred in students at the University of California in Berkeley and at the University of California Medical Center in San Francisco during the period from July 1942 to March 1944 . All the patients were between 19 and 27 years of age. Ten of them were males. The single fatal case occurred at Letterman General Hospital.

Isolation of virus. Specimens of sputum or lung were ground with alundum, diluted with broth to 10 or 20 per cent suspensions, lightly centrifuged, and inoculated intranasally in $0.4 \mathrm{ml}$. amounts into cotton rats under ether anesthesia. Animals were sacrificed 7 to 14 days later, and the result was interpreted as positive when a definite area of pulmonary consolidation was present. Attempts to produce similar consolidation consistently by passage of lungs have, to date, failed or have been masked by the acquisition of other viruses, presumably of animal origin.

For this reason, isolation and passage in the amniotic sac of chick embryos has been used for most purposes. One strain was adapted to eggs from a sterile specimen of human lung without filtration. Two other strains were derived from sputum specimens which had been filtered through collodion membranes of $600 \mathrm{~m} \mu$ average pore diameter. Passage has been made in 11- or 12-day-old embryos at 5-day intervals, amniotic membrane, trachea, and lungs being ground together for passage material. Presence of virus was detected by inoculating suspensions of these tissues intranasally into hamsters or cotton rats. Pulmonary consolidation like that following sputum inoculation was observed if virus was present in sufficient amounts.

Neutralization tests. Suspensions of chick embryo tissues, previously tested for ability to produce pulmonary consolidation in test animals, were mixed with an equal volume of serum. Acute and convalescent sera were inactivated and diluted with an equal volume of horse serum before mixing with the virus suspension, the test serum dilution being 1:4. After 20 minutes' incubation at room temperature, these suspensions were inoculated intranasally into hamsters or cotton rats. Four animals were tested with each suspension. Hamsters were sacrificed at 7 days and cotton rats at 12 to 14 days. The results were expressed as a fraction, the numerator indicating the number of animals showing pulmonary consolidation, and the denominator, the total number tested. A mixture of the original virus suspension with an equal amount of horse serum served as virus control, while a suspension of normal amniotic membrane, trachea, and lungs and an equal amount of horse serum served as animal control. Because the virus is labile, animals receiving the convalescent serum suspension were always inoculated before those receiving the acute serum suspension. Results of neutralization tests, together with certain clinical and laboratory findings, are presented in Table $\mathbf{I}$.

TABLE I

Summary of certain clinical and laboratory findings, cold agglutination tests, results of inoculation of sputum into cotton rats, and neutralization tests in 16 cases of primary atypical pneumonia

\begin{tabular}{|c|c|c|c|c|c|c|c|c|c|}
\hline \multirow[b]{2}{*}{ Case } & \multirow{2}{*}{$\begin{array}{l}\text { High- } \\
\text { est } \\
\text { temp. }\end{array}$} & \multirow{2}{*}{$\begin{array}{c}\text { Dura- } \\
\text { tion } \\
\text { of } \\
\text { fever }\end{array}$} & \multirow[b]{2}{*}{$\begin{array}{l}\text { White blood } \\
\text { cell range }\end{array}$} & \multirow[b]{2}{*}{$\begin{array}{l}\text { Lobes } \\
\text { involved }\end{array}$} & \multicolumn{2}{|c|}{ Cold agglutinin titers } & \multirow{2}{*}{$\begin{array}{c}\text { Result } \\
\text { of in- } \\
\text { ocula- } \\
\text { tion of } \\
\text { sputum } \\
\text { into } \\
\text { cotton } \\
\text { rats }\end{array}$} & \multicolumn{2}{|c|}{$\begin{array}{c}\text { Neutralization } \\
\text { tests }\end{array}$} \\
\hline & & & & & Day bled & Titer & & $\begin{array}{l}\text { Acute } \\
\text { serum }\end{array}$ & $\begin{array}{l}\text { Con- } \\
\text { vales: } \\
\text { cent } \\
\text { serum }\end{array}$ \\
\hline $\begin{array}{l}\mathrm{Ir} \\
\mathrm{Ki} \\
\mathrm{Pa} \\
\mathrm{Gi} \\
\mathrm{Yo} \\
\mathrm{Sn} \\
\mathrm{Mu} \\
\mathrm{Bu}\end{array}$ & $\begin{array}{l}{ }^{\circ} F \\
104 \\
103.6 \\
101 \\
103.6 \\
104 \\
104 \\
104 \\
104.8\end{array}$ & $\begin{array}{r}\text { days } \\
9 \\
14 \\
12 \\
9 \\
9 \\
10 \\
14 \\
24\end{array}$ & $\begin{array}{c}5,800 \text { to } 9,600 \\
8,800 \text { to } 9,550 \\
9,300 \\
8,450 \\
5,500 \text { to } 12,400 \\
4,950 \\
5,100 \text { to } 8,300 \\
7,750 \text { to } 37,600\end{array}$ & $\begin{array}{l}\text { RLL } \\
\text { RML, RLL } \\
\text { RML } \\
\text { RLL, LLL } \\
\text { RUL, RLL } \\
\text { RLL } \\
\text { RUL } \\
\text { RLL, RUL, LLL, }\end{array}$ & $\begin{array}{l}5^{*}, 37 \dagger \\
7^{*}, 43 \dagger \\
7^{*}, 13,27 \dagger \\
3^{*}, 11,37 \dagger \\
4^{*}, 16,26,80 \dagger \\
6^{*}, 9,16 \dagger \\
4^{*}, 12,18 \dagger \\
4^{*}, 12,25 \dagger, 46 \dagger\end{array}$ & $\begin{aligned} & 10,80,40 \\
< & 10,40,40 \\
< & 10,2,560,640,320 \\
< & 10,80,320 \\
< & 10,40,1,280 \\
< & 10,80,160,20\end{aligned}$ & $\begin{array}{l}2 / 2 \\
2 / 4 \\
1 / 2 \\
4 / 6 \\
7 / 12 \\
2 / 2 \\
6 / 9 \\
5 / 9\end{array}$ & $\begin{array}{l}3 / 4 \\
2 / 8 \\
6 / 7 \\
2 / 4 \\
3 / 8 \\
2 / 4 \\
6 / 7 \\
6 / 11\end{array}$ & $\begin{array}{l}0 / 4 \\
0 / 8 \\
0 / 7 \\
0 / 4 \\
0 / 8 \\
0 / 4 \ddagger \\
0 / 7 \\
0 / 11 \ddagger\end{array}$ \\
\hline $\begin{array}{l}\text { So } \\
\text { Do } \\
\text { Hu } \\
\text { Kr } \\
\text { Mur } \\
\text { Ta } \\
\text { Pg } \\
\text { De\|l }\end{array}$ & $\begin{array}{l}102 \\
101.8 \\
104.8 \\
101.4 \\
101.8 \\
103.4 \\
101 \\
105.4\end{array}$ & $\begin{array}{r}8 \\
16 \\
19 \\
7 \\
8 \\
16 \\
8 \\
12\end{array}$ & $\begin{array}{r}8,200 \text { to } 13,200 \\
10,000 \text { to } 7,900 \\
7,650 \text { to } 11,600 \\
6,600 \text { to } 10,700 \\
9,100 \text { to } 8,900 \\
8,200 \text { to } 13,100 \\
8,200 \\
8,000 \text { to } 22,000\end{array}$ & $\begin{array}{l}\text { LLL } \\
\text { LLL, RLL } \\
\text { RLL, LLL } \\
\text { LLL } \\
\text { RLL } \\
\text { RLL } \\
\text { RML } \\
\text { LLL, LUL, RLL, } \\
\text { RML, RUL }\end{array}$ & $\begin{array}{l}7^{*}, 12,19,27 \dagger \\
8^{*}, 14,21,28 \dagger \\
7^{*}, 14,21,28 \dagger \\
7^{*}, 16 \dagger, 76 \\
6^{*}, 15 \dagger, 60 \\
4^{*}, 10,19,31 \dagger \\
5^{*}, 11,21,50 \dagger\end{array}$ & $\begin{array}{r}20,320,160,80 \\
5,40,160,160 \\
<10,320,160,80 \\
<10,160,10 \\
<10,80,10 \\
<10,10,80,80 \\
<10,80,80,40\end{array}$ & $\begin{array}{l}6 / 10 \\
1 / 4 \\
8 / 27\end{array}$ & $\begin{array}{l}3 / 3 \\
4 / 4 \\
1 / 4 \\
3 / 8 \\
3 / 4 \\
4 / 48 \\
3 / 48\end{array}$ & $\begin{array}{l}0 / 3 \ddagger \\
0 / 4 \ddagger \\
0 / 4 \\
0 / 8 \ddagger \\
1 / 4 \\
0 / 4 \\
0 / 4\end{array}$ \\
\hline
\end{tabular}

* Acute serum. † Convalescent serum specimen used in neutralization tests. † Serum shown by subsequent test to neutralize at dilution of $1: 16$ or more. $\$$ Neutralization test done in chick embryos. II Died.

In the last three columns numerator indicates number of positive animals; denominator the total number tested. 


\section{CLINÍCAL PICTURE}

The onset of the disease was, in most instances, gradual. Presenting symptoms most frequently noted were malaise, cough, feverishness, headache, and moderate aching. Chilly sensations were common, but true chills infrequent. Sore throat, if present, was not severe (15). Pleuritic pain was not noted, though chest pain, either retrosternal in location or felt along the costal margin, was present in several instances. Cough was often troublesome and persistent. Sputum was scanty, usually tenacious, greenish in color, and occasionally streaked with bright red blood. On physical examination, the patient did not appear severely ill unless considerable areas of lung were involved. Slight dulness and scattered moist râles were often the only findings on examination of the chest. Later in the course of the disease coarse râles were heard and signs of consolidation sometimes appeared.

Admission white blood cell counts ranged from 4,950 to 10,000 . As the illness progressed, particularly when it was severe, the white blood cell count tended to rise. Thus, in the single fatal case (De) it rose to 22,000 before death, and in another extremely severe case $(\mathrm{Bu})$ a count of 37,500 was recorded at the height of the disease. Sputum cultures revealed only the usual pharyngeal organisms. Stained smears showed few bacteria and a relatively sparse cellular exudate in which mononuclear cells were common. $\mathrm{X}$-rays of the lungs showed small or extensive infiltrations. Lateral films were often of value in disclosing minimal lesions. Not infrequently, the areas of pneumonia continued to spread for several days or new areas were noted, but the migratory type of pneumonia was uncommon.

The temperature curve was either very irregular or fairly sustained, and usually fell by lysis. Most patients began to show clinical improvement and clearing of $x$-ray findings within 10 days of onset. At no time did they appear very ill. In others, however, the pneumonic process continued to spread and the patients became desperately ill and showed intense dyspnea and cyanosis. The one fatal case was remarkable in that within 11 days the pneumonia had involved most of one lung and more than half of the other. Herpes labialis was noted in patients with high fever. The spleen was palpable in one patient (Yo) during the first week of illness. Disturbance of cerebral functions was infrequent even in those patients who were most seriously ill. Convalescence was slow, many patients complaining of weakness, dyspnea on exertion, and persistent cough. No other sequelae have been observed.

\section{CASE SUMMARIES}

Three cases are presented in detail. The first, a comparatively mild one, was selected as an example of the type of case most frequently seen. The second case, which was extremely severe, and the third, which terminated fatally, represent less common types, but present a number of points of unusual interest. Clinical data on these 3 and 13 other cases are presented in Table I.

Case 1. Gi, a male, aged 22, awoke on March 21, 1943, with a tickling sensation in his throat. That evening he felt feverish and complained of generalized aching and malaise. Next day these symptoms were more pronounced and a troublesome cough had developed which produced small amounts of tenacious greenish sputum. It is of interest that the patient's brother, with whom he was living, had previously suffered a similar attack of primary atypical pneumonia, beginning on March 1, 1943, and had shown a rise in cold agglutination titer from less than 10 during the acute phase to $\mathbf{4 0}$ during convalescence. The 2 brothers were in contact with each other until March 9.

On admission to the University of California Hospital on March 22, the patient's temperature was $103.6^{\circ} \mathrm{F}$., pulse 100 , respirations 20 , and blood pressure $108 / 80$. He did not appear acutely ill, but complained of severe generalized headache, retro-orbital soreness, and occasional pain in his right ear. His skin was hot and dry, his nose moderately congested; but no other symptoms were noted.

Course: On March 24, slight dulness and a few crackling râles were noted at the base of the right lung. These became more prominent during the following days. The temperature remained elevated until March 29, with daily peaks of $102.2^{\circ}$ or more, and fell by lysis. Throughout this period, the patient felt and looked comfortable and continued to eat well. Headache and cough were the most troublesome symptoms. Recovery was fairly rapid.

Laboratory findings: On March 23, the blood count showed 5,000,000 red blood cells (hemoglobin 14 grams) and 8,450 white blood cells with 70 per cent polymorphonuclears (F./N.F. 34/36). Sputum examination was negative for pneumococci and acid-fast bacilli. Chest $x$-ray on March 23 showed a small patch of pneumonitis in the right lower lung in the cardiohepatic angle. On March 29, this area had spread and involved a good deal of the right lower lobe and there was evidence of minimal spread to the 
middle of the left lung. On April 22, the lungs appeared normal.

Suspensions of sputum collected on the fourth day of disease produced pulmonary lesions in 4 of 6 cotton rats. Cold agglutination titers (as shown in Table $\mathrm{I}$ ) of serum specimens taken on the third, eleventh, and thirty-seventh days of disease were less than 10,40 , and 40 , respectively.

Case 2. Bu, a female, aged 20, noted aching and malaise on April 26, 1943. During the following 2 days, these symptoms became more troublesome, and in addition she complained of cough, feverishness, restlessness, and anorexia. Slight wheezing with respiration was noticed. She was admitted to Cowell Memorial Hospital on April 29.

Physical examination: The patient's temperature was $100.2^{\circ} \mathrm{F}$., pulse 84 , respirations 22 . She did not appear acutely ill. Cough was frequent and produced moderate amounts of tenacious, yellowish sputum. Conjunctivae and pharynx were injected. Fine and coarse râles were heard over the right lower lobe as far anteriorly as the axillary line.

Course: The high, spiking temperature curve is reproduced in Figure 1. On May 1, bronchial breathing was heard over the right lower lobe and the patient was placed in an oxygen tent. On May 5, dulness was noted over the right lower lobe and bronchial breathing was heard over most of the right lung and over the upper half of the left lung. On May 6, respirations were wheezing in character. By May 7, respirations had risen to 38 , cyanosis was marked, and the patient appeared seriously ill. On May 9, $200 \mathrm{ml}$. of pooled plasma from 3 patients recently convalescent from primary atypical pneumonia, who had shown significant cold agglutinin titers, were given intravenously. On the next day, the patient appeared somewhat more alert and $300 \mathrm{ml}$. more of the same pool of plasma were given. One hour later, her pulse had risen to 140 and she was apprehensive and sweating profusely. That evening, the respiratory rate was 50 , pulse 156, and the patient appeared moribund. She remained in an extremely critical state throughout the next day, and then slowly improved. Her temperature meanwhile had fallen and subsequently did not exceed $101^{\circ}$, though another 10 days passed before it returned to normal. Convalescence was slow, but at last report there were no sequelae. Sulfadiazine was given from May 3 to May 10, the blood level on May 4 being $7.1 \mathrm{mgm}$. per cent. No effect on the course of the illness was seen.

Laboratory findings: Admission white blood cell count was 7,750. As the illness progressed, the count rose steadily. On May 9, it was 17,200, with polymorphonuclears constituting 86 per cent (F./N.F. 56/30). On May 12 , it was 37,600 . It dropped to 24,400 on May 15 , to 19,700 on May 20, and to 9,200 on May. 30. Sputum cultures showed a growth of Staphylococcus aureus and -alpha streptococci, but were negative for pneumococci, beta streptococci, and acid-fast bacilli.

Chest x-ray on April 29 showed a fairly extensive pneumonic area at the base of the right lung, lobar in character, and mottling near the left hilum. On May 6, films showed an extensive pneumonia involving much of the right lung and the middle portion of the left lung. On June 3, there was much clearing, but slight residual infiltration on both sides. On June 11, clearing was more complete, but an area of increased density, which suggested fibrosis, remained at the left apex.

Sputum collected on April 29 and May 6 was tested in cotton rats. The results with both specimens were positive, 5 out of 9 animals showing pulmonary consolidation. Later, this material was passed through a collodion membrane of $600 \mathrm{~m} \mu$ pore diameter, and the virus was adapted to chick embryos. This strain has been carried through 25 passages and is neutralizable by the convalescent sera of this and other patients with atypical pneu-

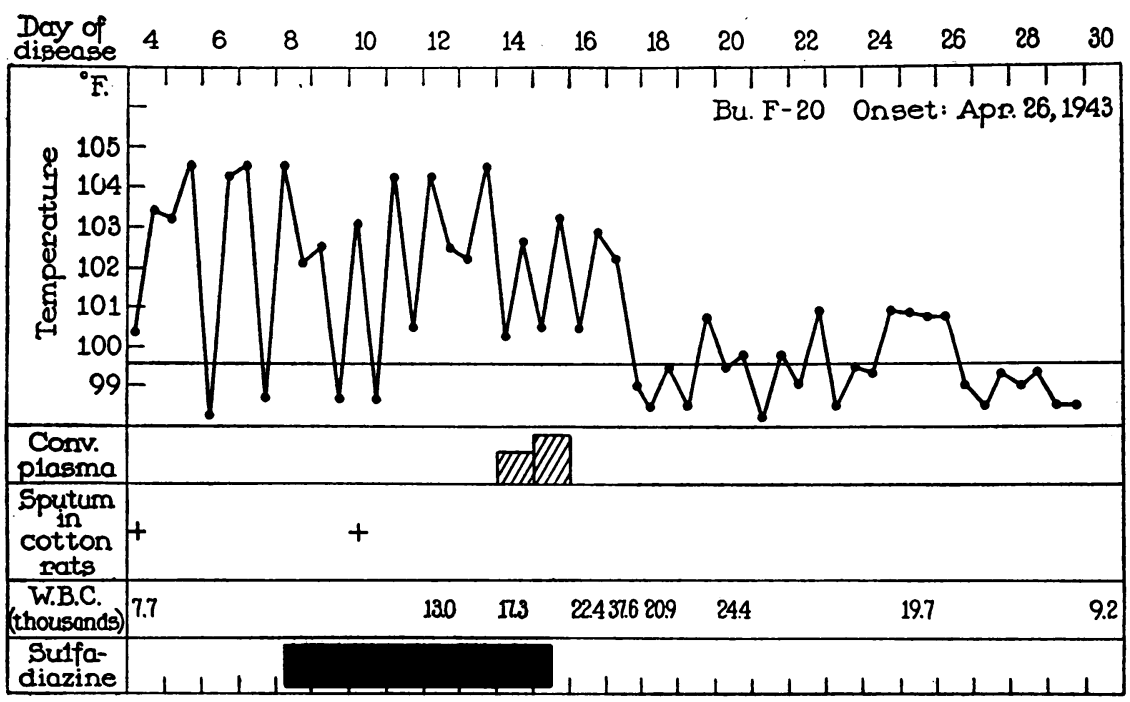

Fig. 1. Temperature Record of Patient (Bu) Whose Illness Was Unusually Severe 
monia. The acute serum does not neutralize the virus. The results of serial cold agglutination tests are recorded in Table $I$.

Case $3 .^{3}$ De, a male, aged 26 , was admitted to Letterman General Hospital on November 11, 1942, with a history of an illness of 4 days' duration. Complaints during this period were coryza, sore throat, cough, feverishness, malaise, generalized muscular pains, and anorexia. Symptoms had become markedly worse on the day of admission.

Physical examination: The patient's skin was hot and dry. The right nostril was obstructed and the pharynx injected. Respiratory movements were equal and shallow because deeper respiration incited cough and pain in chest. Slight dulness to percussion was noted at the bases of both lungs, and many fine moist râles were heard throughout the lungs, particularly at the bases. Blood pressure was $118 / 50$. Examination of the heart showed it to be normal.

Course: Fever remained high, with peaks reaching $105^{\circ} \mathrm{F}$. The patient soon became markedly dyspneic and cyanotic and was placed in an oxygen tent. Signs of pneumonia became more prominent over the right upper lobe and the whole left side. The cough was troublesome, but virtually no sputum was raised. Sulfadiazine was given throughout hospitalization in doses of 1 gram every 4 hours and an adequate blood level was obtained, but no effect was apparent. Dyspnea became progressively worse, and the patient died on November 17.

Laboratory findings: Admission blood count showed $3,770,000$ red blood cells and 8,000 white blood cells, with normal distribution. Subsequently, the white blood cells rose to 11,000 , to 16,000 , and finally to 22,000 on November 16. Urinalysis showed albumin $(+t)$. Throat swabs and a single sputum examination failed to show pneumococci. Chest $x$-ray taken on November 11 revealed an extensive bronchopneumonia in the left lower lobe. On November 15, x-ray showed an extremely extensive bronchopneumonia involving both lobes on the left and parts of all three right lobes.

Autopsy findings: Post-mortem examination was made within 1 hour after death. Intestines were markedly distended. A slight excess of blood-tinged fluid was found deep in the peritoneal cavity. Both pleural cavities contained about $200 \mathrm{ml}$. of slightly blood-tinged fluid. The pericardial cavities contained about $200 \mathrm{ml}$. of pale straw-colored fluid.

The right lung weighed 1,085 grams, the left 945 grams. The lungs were similar. On palpation, from apex to base, there were noted innumerable distinct and confluent soft and firm nodules, which varied from about 1 to $4 \mathrm{~cm}$. in diameter. Lymph nodes at the hilum were somewhat enlarged, soft, and greyish between the areas of pigmentation. Bronchi were distended with yellow, purulent, frothy exudate. Beneath the pleura the nodular foci appeared as lighter or darker areas against the slate-grey

${ }^{3}$ This case is reported through the courtesy of the Medical. and Laboratory Branches, Letterman General Hospital, from whom the clinical and pathological findings were obtained. background. Except for a number of areas over the left lung, where dull and granular areas were covered with a pinkish-red exudate, the pleura was smooth and showed no exudate. On cut surface, the nodular areas could be seen as distinct or confluent, frequently poorly circumscribed, dry granular foci of irregular size and shape, which stood above the cut surface of the lung. The nodules were sometimes pink and duller than the surrounding tissue. Some were grey and many had a yellowish cast, as though slightly broken down. This pneumonic process extended from apex to base, involving all lobes.

The heart weighed 430 grams. The right auricle and ventricle were markedly dilated. The coronary arteries were smooth, and the lumens were patent. The myocardium was red and of good tone. The spleen weighed 250 grams. The cut surface showed a soft grumous red pulp, and the follicles were not observed. The brain weighed 1,640 grams. Cerebral vessels were markedly congested, particularly the pial vessels. Other organs showed nothing noteworthy.

Microscopic examination: All sections (Figure 2) taken from different portions of the two lungs showed a pneumonic reaction which might be classified as an atypical bronchopneumonia. Practically all combinations of cellular, fibrinous, and serous exudate could be found in the various alveoli, the exudate in some appearing fresh, while in others it seemed to be undergoing resolution. In some sections, the character of the pneumonia was that of a discrete bronchopneumonia. In other areas, the pneumonia was of the confluent bronchopneumonic type.

Certain features in the inflammatory reaction were of interest. In the first place, there was a good deal of fibrin present, much of which was distributed peripherally and appeared tightly adherent to the inner wall of the alveolus. In the second place, there were certain areas in which it seemed that the exudate was breaking down and abscesses were forming. In these areas, the exudate was cellular, of ten consisting predominantly of polymorphonuclear leukocytes. Necrosis of the alveolar walls had apparently occurred and the center of the pneumonic focus seemed to be undergoing liquefaction. A third point of interest was that in certain areas the exuda te appeared to be undergoing organization, the process consisting almost exclusively of invasion by young fibroblasts with no proliferating capillaries observable. A fourth point of interest was the marked morphological change which had taken place in the epithelial lining of a few of the bronchi. Here the epithelial lining had changed wholly or in part to a stratified squamous type. The appearance of the epithelial lining of these bronchi was that of a pavement type of epithelium with loss of cilia, squamous cells on the surface, and prickle cells interspersed in the deeper layers. Mitotic figures were extremely numerous. In several sections showing strips of pleura, the pleura was practically always free of exudate.

The coronary arteries were normal. Sections of myocardium revealed sporadic degenerated and necrotic muscle fibres, some being lumpy and pale, and in certain instances 


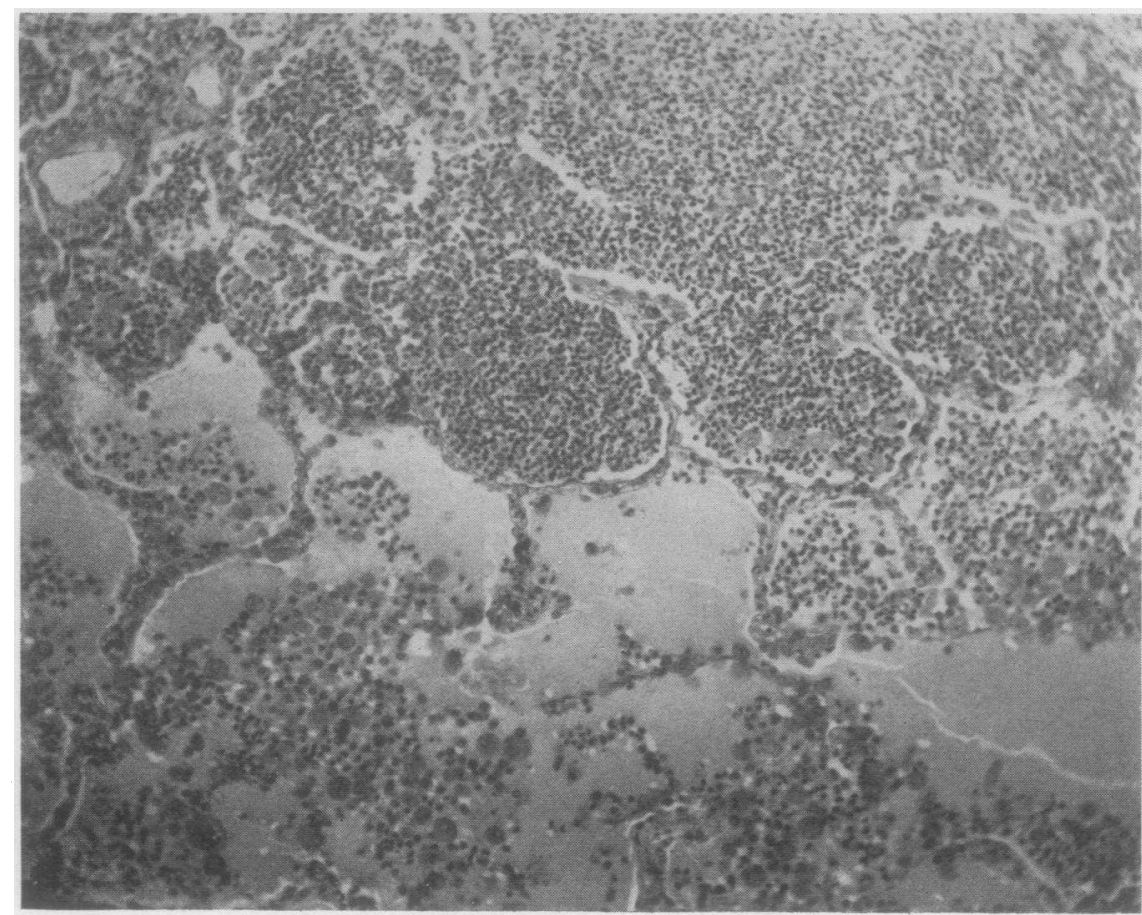

PLATE 1. Section from edge of a small discrete pneumonic focus, showing dense cellular exudate in alveoli in upper portion and comparatively sparse cellular exudate with numerous macrophages in lower portion. $\times 120$.

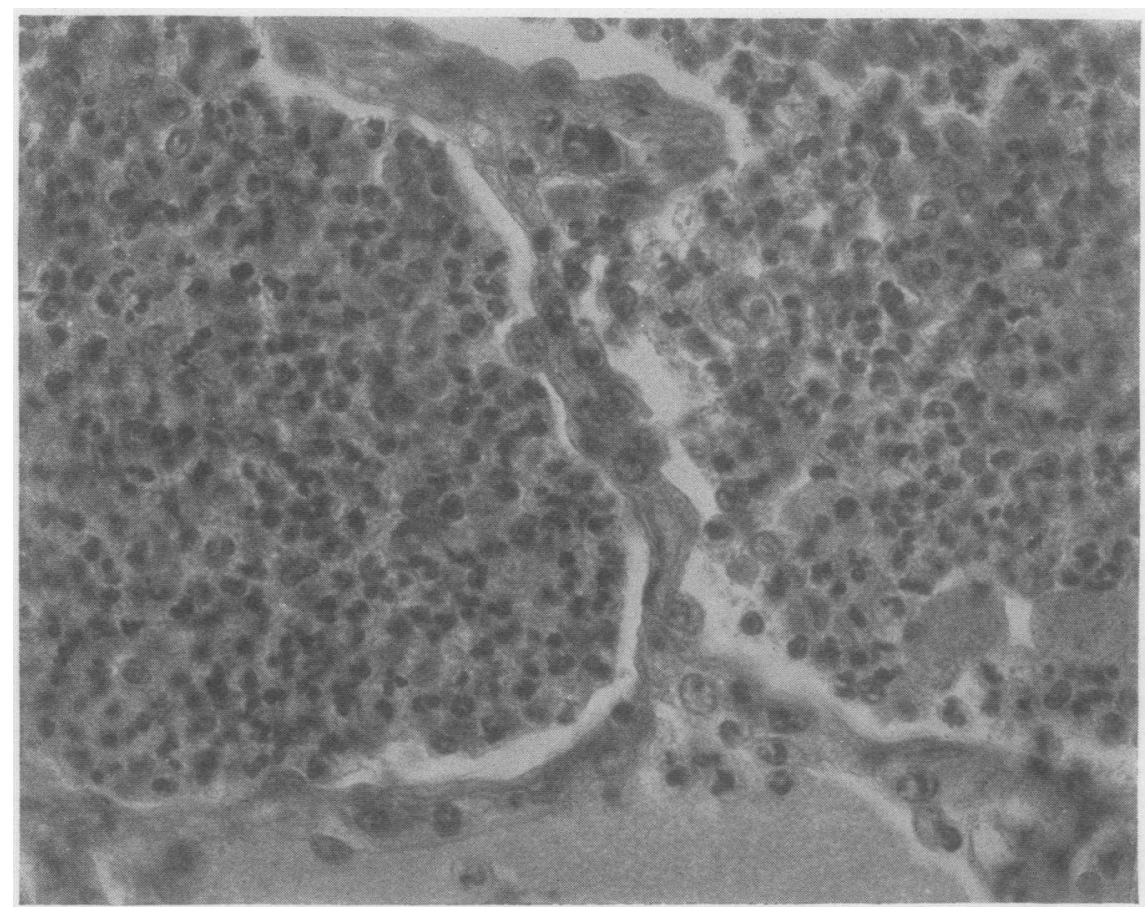

PLATE 2. High magnification of same section, showing composition of alveolar exudate. Small mononuclear and polymorphonuclear cells predominate and occasional macrophages are seen. The alveolar septa are not markedly thickened. $\times 400$. 


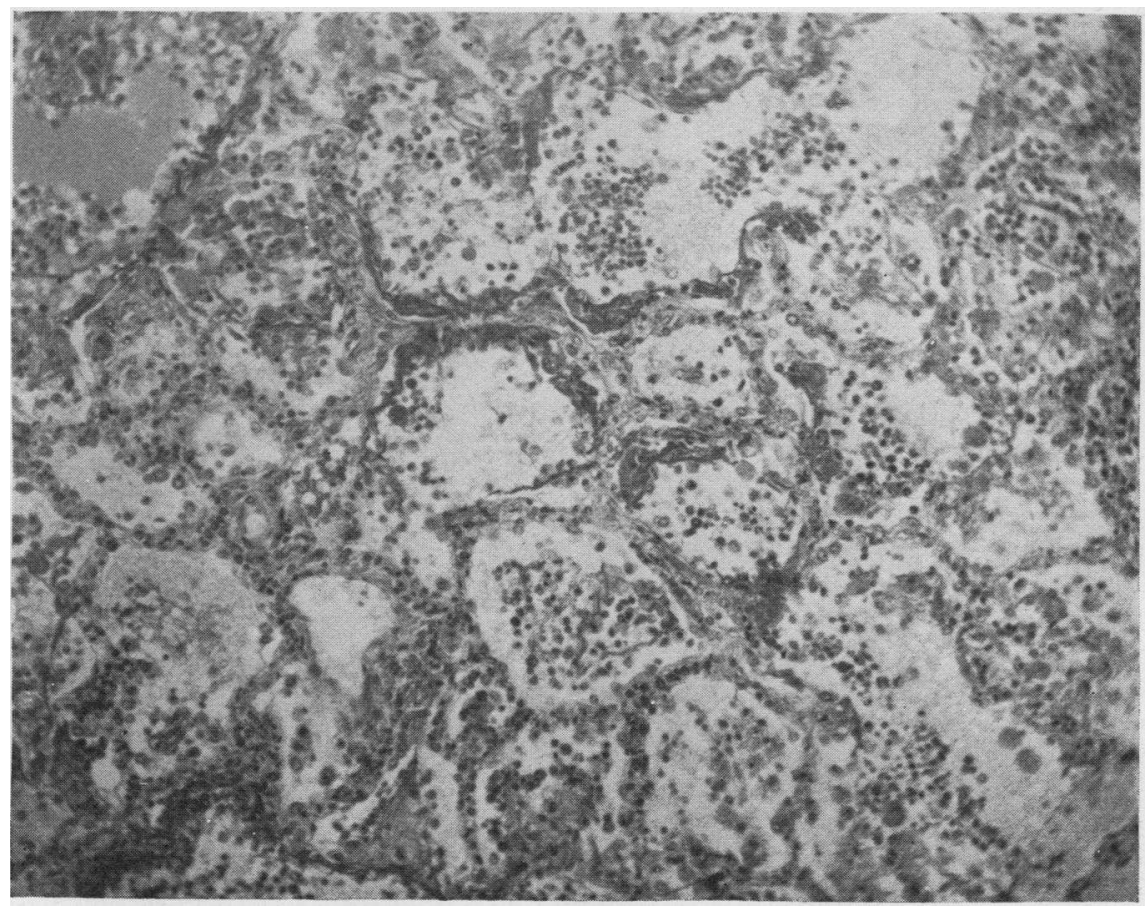

PLATE 3. Section from another area, showing fibrin distributed peripherally along some of the alveolar walls. The exudate in this area is less cellular. $\quad \times 120$.

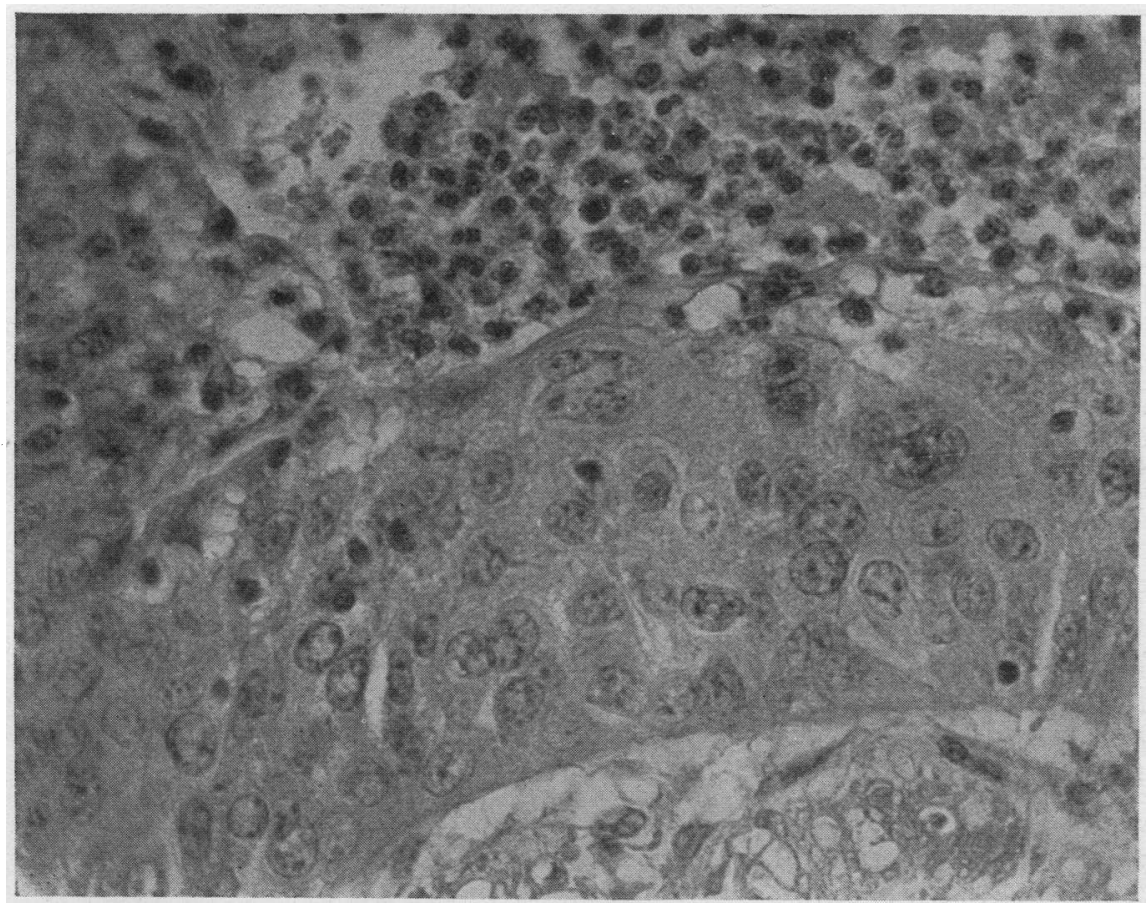

PLATE 4. Section showing metaplasia of the bronchial epithelium. The ciliated columnar epithelium has changed to an irregular stratified squamous type. $\times 400$.

Fig. 2. Sections from lungs of Patient (De) with fatal Case of Primary Atypical Pneumonta. Sections Stained with Hematoxylin a.d Eosin 
showing loss of striation. The small capillaries of the myocardium were markedly congested, and some contained numerous leukocytes. In one or two sections, leukocytes were present in the somewhat edematous interstitial tissue outside the capillary walls. There were, however, no definite areas of infarction and no specific rheumatic nodules. Sections from other organs showed nothing noteworthy.

Etiological studies: Cultures of lung tissues remained sterile after 72 hours. Impression smears showed no bacteria or elementary bodies. Suspensions tested intranasally in cotton rats produced pulmonary lesions in 8 of 27 animals. Without filtration, the virus in the human lung suspension was adapted to the amniotic sac of chick embryos and has been carried through 45 passages. This procedure was subsequently repeated. Suspensions of amniotic membrane, lungs, and trachea retain their infectivity for cotton rats and hamsters and are neutralized by convalescent serum from other persons who have had primary atypical pneumonia. The properties of the virus isolated from this patient have been described in detail in a separate publication (12). A cold agglutination test run with serum pipetted from the lung specimen showed a titer of less than 10.

\section{DIFFERENTIAL DIAGNOSIS}

An attempt to differentiate primary atypical pneumonia from other diseases is rendered difficult by the fact that several diseases of different etiology have been included under this heading. The observations which follow will therefore be restricted to the type of the disease prevalent in the area which the cases described in this report represent. While these cases present a fairly characteristic picture, the number of the diseases which may cause difficulty in diagnosis is very large. Thus, mild cases with slight or, perhaps, no pulmonary involvement may closely resemble certain nonbacterial upper respiratory infections, particularly influenza and other influenza-like diseases.

The more familiar form of the disease, with slight or extensive pulmonary involvement, must be distinguished on the one hand from bacterial and mycotic pneumonias, and on the other from pneumonias due to other viruses and rickettsiae. Pneumococcal lobar pneumonia presents several features very uncommon in primary atypical pneumonia, notably pleuritic pain, rusty sputum, and leukocytosis early in the disease. Bronchopneumonias due to pneumococci, streptococci, staphylococci, and other bacteria may cause more difficulty. Those primary atypical pneumonias restricted to upper lobes or presenting a very diffuse pneumonia may closely resemble pulmonary or miliary tuberculosis. The picture of primary coccidioidal pneumonia may be very similar, and isolation of Coccidioides immitis and serological tests may be necessary for differential diagnosis (16). It is possible that the cold agglutination test may prove extremely useful in separating out the primary atypical pneumonias, but further substantiation of this point is needed.

The clinical differences between primary atypical pneumonia and pneumonias due to psittacosis-like viruses or $Q$-fever are sometimes too slight to permit differentiation, but suspicion may be directed toward the psittacosis group when a severely ill patient shows marked impairment of cerebral function and prominent gastro-intestinal symptoms, and appears gravely ill despite the fact that the area of lung involved is comparatively limited. A history of avian contact should be sought. Laboratory procedures, including isolation of virus and demonstration of an increase in antibody to the agent in question are usually required.

\section{TREATMENT}

Symptomatic therapy, directed chiefly toward relieving headache and cough, was used in all cases. Only in the most severe cases were sulfonamides employed, and in no instance was any response observed. Oxygen was administered to 6 patients and appeared to have a beneficial effect. One patient $(\mathrm{Bu})$ received a pool of convalescent plasma from patients who had previously shown high cold agglutinin titers. Her temperature fell after the second transfusion, but her condition never appeared worse than during the following day. X-ray therapy was not tried.

\section{DISCUSSION}

The cases of primary atypical pneumonia studied at this laboratory can be divided into two main groups: (1) a large group presenting the same general characteristics as the cases described above, and (2) single cases or small groups of cases due to a variety of agents, in some instances psittacosis-like viruses, in others unknown agents. While the occurrence of clear-cut epidemics of the former type suggests a single 
etiology, it is by no means certain that the group is homogeneous with respect to its etiology. The data presented in this paper and in a previous publication indicate that a substantial proportion of the cases of this type on which neutralization tests have been done are due to this new atypical pneumonia virus. It has already been shown that the virus can cause an illness which varies in severity from a comparatively mild one to an extremely severe or, in rare instances, a fatal one. The number of cases studied is small, however, and no definite statement can be made at the present time concerning the frequency of infection with the virus in this and other areas.

The occurrence of cold agglutinins in the sera of most of those patients whose illness was shown to be due to the new virus raises the question whether a significant increase in cold agglutinin titer following a respiratory disease represents a specific response to a single etiological agent or a relatively nonspecific response to any one of a number of agents. The cold agglutination tests done in this laboratory on a large number of sera from patients in the first group have shown that more than half of the persons studied developed significant (40 or more) titers during the latter part of their illness or during convalescence. Certain other patients with clinically similar cases did not. Further combined cold agglutination tests and etiological studies must be made before it is possible to state in what proportion of pneumonias due to this virus cold agglutinin titers rise. The frequency of high cold agglutinin titers in pneumonias and upper respiratory infections due to other agents likewise remains to be determined. Even in our present state of knowledge, however, the test has proved very useful, possessing the great advantage of simplicity of performance. Its chief disadvantage lies in the fact that titers return to within normal limits in a relatively short time, thus curtailing its usefulness in epidemiological investigation.

The comparatively infrequent cases comprising the second group in which the etiology has been determined represent, for the most part, infections with viruses or rickettsiae present in a variety of species of birds, mammals, or arthropods, or occur as laboratory infections. As a group, they tend to be more severe and not in- frequently terminate fatally. The largest number is caused by viruses in the psittacosis group, 3 of which have been isolated from human patients, namely psittacosis, the pigeon ornithosis virus, and the S-F strain $(13,17)$. Because of certain similarities in the clinical picture, incubation period, and pathological findings observed in psittacosis-like infections and in the prevalent type of primary atypical pneumonia, it has been suggested that these or related agents play an important part in the etiology of primary atypical pneumonia $(17,18)$. Evidence to support such a hypothesis is at present lacking. In this laboratory, less than 10 per cent of more than 250 cases studied have been shown to be due to viruses in the psittacosis group. We have not observed pneumonias due to the rickettsia of $Q$-fever or infections with the lymphocytic choriomeningitis virus in which pulmonary consolidation occurred.

Specimens of lung tissue from a considerable number of persons, in which a bacterial etiology has been definitely excluded, have failed to yield any of the viruses mentioned in this paper. This fact, together with certain observations, such as that (19) of a pneumonia of infants characterized by eosinophilic inclusion bodies, makes it seem probable that a number of nonbacterial infectious agents capable of causing pneumonia remain to be discovered.

\section{SUMMARY}

1. Clinical and laboratory data have been presented on 16 cases of primary atypical pneumonia assumed to be due to a recently isolated virus.

2. This atypical pneumonia virus is transmissible to chick embryos, cotton rats, and hamsters and is apparently not related to previously described viruses isolated from cases of atypical pneumonia.

3. The clinical picture did not differ in significant respects from that presented in other reports of epidemics of primary atypical pneumonia.

4. The pathological findings in a fatal case from which virus was isolated have been described.

5. Significant titers of cold agglutinins were demonstrated in the convalescent serum speci- 
mens of all 13 patients in whom this test was performed.

The authors wish to acknowledge the cooperation of Drs. W. G. Donald, R. T. Sutherland, M. G. Zeff, and A. H. Schaeffer, and Mrs. Elva May, of Cowell Memorial Hospital; and of Drs. W. J. Kerr, Saxton J. Pope, and Ellen Brown, of the University of California Medical School. Valuable technical assistance was provided by Miss M. Corey and Miss V. L. Hanford.

\section{BIBLIOGRAPHY}

1. For review of literature and detailed bibliography, see Dingle, J. H., and Finland, M., Medical progress; virus pneumonias; primary atypical pneumonias of unknown etiology. New England J. Med., 1942, 227, 378.

2. Stokes, J., Jr., Kenney, A. S., and Shaw, D. R., New filtrable agent associated with respiratory infections. Tr. and Stud., Coll. Physicians, Philadelphia, 1939, $6,329$.

3. Weir, J. M., and Horsfall, F. L., Jr., Recovery from patients with acute pneumonitis of virus causing pneumonia in the mongoose. J. Exper. Med., 1940, $72,595$.

4. Dyer, R. E., Topping, N. H., and Bengtson, I. A., Institutional outbreak of pneumonitis; isolation and identification of causative agent. Pub. Health Rep., 1940, 55, 1945.

5. Eaton, M. D., Beck, M. D., and Pearson, H. E., Virus from cases of atypical pneumonia. J. Exper. Med., 1941, 73, 641.

6. Meyer, K. F., Pigeons and barnyard fowls as possible sources of human psittacosis or ornithosis. Schweiz. med. Wchnschr., 1941, 71, 1377.

7. Smadel, J. E., Green, R. H., Paltauf, R. M., and Gonzales, T. A., Lymphocytic choriomeningitis; 2 human fatalities following unusual febrile illness. Proc. Soc. Exper. Biol. and Med., 1942, 49, 683.
8. Johnson, H. N., quoted by Dingle, J. H., and others. Primary atypical pneumonia, etiology unknown. War Med., 1943, 3, 223. Also personal communication to M. D. Eaton.

9. Horsfall, F. L., Jr., Curnen, E. C., Mirick, G. S., Thomas, L., and Zeigler, J. E., A virus recovered from patients with primary atypical pneumonia. Science, 1943, 97, 289.

10. Smadel, J. E., Atypical pneumonia and psittacosis. J. Clin. Invest., 1943, 22, 57.

11. Eaton, M. D., Meiklejohn, G., van Herick, W., and Talbot, J. C., Infectious agent from cases of atypical pneumonia apparently transmissible to cotton rats. Science, 1942, 98, 518.

12. Eaton, M. D., Meiklejohn, G., and van Herick, W., Studies on the etiology of primary atypical pneumonia; a filterable agent transmissible to cotton rats, hamsters, and chick embryos. J. Exper. Med., 1944, 79, 649.

13. Meiklejohn, G., Beck, M. D., and Eaton, M. D., Atypical pneumonia caused by psittacosis-like viruses. J. Clin. Invest., 1944, 23, 167.

14. Meiklejohn, G., Cold agglutination test in diagnosis of primary atypical pneumonia. Proc. Soc. Exper. Biol. and Med., 1943, 54, 181.

15. Young, L. E., Storey, M., and Redmond, A. J., Clinical and epidemiological features of outbreak of primary atypical pneumonia of unknown etiology among hospital and medical school personnel. Am. J. M. Sc., 1943, 206, 756.

16. Smith, C. E., Coccidioidomycosis. Med. Clin. North America, 1943, 27, 790.

17. Meyer, K. F., Ecology of psittacosis and ornithosis. Medicine, 1942, 21, 175.

18. Favour, C. B., Ornithosis (psittacosis); report of 3 cases and historical, clinical, and laboratory comparison with human atypical (virus) pneumonia. Am. J. M. Sc., 1943, 205, 162.

19. Adams, J. M., Green, R. G., Evans, C. A., and Beach, N., Primary virus pneumonitis; comparative study of two epidemics. J. Pediat., 1942, 20, 405. 